\title{
Correction to: Phenotypic characterization of X-linked hypophosphatemia in pediatric Spanish population
}

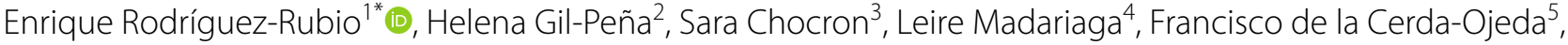 \\ Marta Fernández-Fernández ${ }^{6}$, Carmen de Lucas-Collantes ${ }^{7}$, Marta Gil $^{8}$, María Isabel Luis-Yanes ${ }^{9}$, \\ Inés Vergara ${ }^{10}$, Juan David González-Rodríguez ${ }^{11}$, Susana Ferrando ${ }^{12}$, Montserrat Antón-Gamero ${ }^{13}$, \\ Marta Carrasco Hidalgo-Barquero ${ }^{14}$, Angustias Fernández-Escribano ${ }^{15}$, Mo Ángeles Fernández-Maseda ${ }^{16}$, \\ Laura Espinosa ${ }^{17}$, Aniana Oliet ${ }^{18}$, Antonio Vicente ${ }^{19}$, Gema Ariceta $^{3}$ and Fernando Santos ${ }^{1,2}$ on behalf of \\ RenalTubeGroup
}

\section{Correction to: Orphanet J Rare Dis (2021) 16:104} https://doi.org/10.1186/s13023-021-01729-0

Following the publication of the original article [1] the authors requested to update their funding declarations as follows:

This research has been partially funded by Kyowa Kirin Farmacéutica S.L.U., project PI17/01745 from Instituto de Salud Carlos III, Acción Estratégica en Salud 2017-2020 and FEDER funds, Fondo de Investigaciones Sanitarias (FIS), Fundación Nutrición y Crecimiento (FUNDNYC), Instituto de Investigación Sanitaria del Principado de Asturias (ISPA) and Fundación para la Investigación y la Innovación Biosanitaria del Principado de Asturias (FINBA).

The Funding section has also been updated in the original article.

\section{Author details \\ ${ }^{1}$ Pediatric Research, Medicine Department, University of Oviedo, Oviedo, Spain. ${ }^{2}$ AGC Pediatría, Hospital Universitario Central de Asturias, Oviedo,}

The original article can be found online at https://doi.org/10.1186/s13023021-01729-0.

*Correspondence: erodrr00@gmail.com

1 Pediatric Research, Medicine Department, University of Oviedo, Oviedo, Spain

Full list of author information is available at the end of the article
Spain. ${ }^{3}$ Servicio de Nefrología Pediátrica, Hospital Vall D'Hebron, Universitat Autónoma de Barcelona, Barcelona, Spain. ${ }^{4}$ Servicio Nefrología Pediátrica, IIS Biocruces-Bizkaia, Universidad del País Vasco UPV/EHU, Hospital Universitario Cruces, Barakaldo, Spain. ${ }^{5}$ Unidad de Nefrología Pediátrica, Hospital Virgen del Rocío, Sevilla, Spain. ${ }^{6}$ Servicio Pediatría, Complejo Asistencial Universitario de León, León, Spain. ${ }^{7}$ Servicio Nefrología, Hospital Niño Jesús, Madrid, Spain. ${ }^{8}$ Servicio Pediatría, Hospital Universitario de Santiago de Compostela, Santiago de Compostela, Spain. ${ }^{9}$ Servicio Pediatría, Hospital Universitario Nuestra Señora de Candelaria, Santa Cruz de Tenerife, Spain. ${ }^{10}$ Servicio Pediatría, Complexo Hospitalario Universitario A Coruña (CHUAC), A Coruña, Spain. ${ }^{11}$ Unidad de Nefrología, Hospital General Universitario Santa Lucia, Cartagena, Spain. ${ }^{12}$ Servicio de Pediatría, Hospital Clínico Universitario de Valencia, Valencia, Spain. ${ }^{13}$ Unidad Nefrología Pediátrica, Hospital Universitario Reina Sofa, Córdoba, Spain. ${ }^{14}$ Unidad de Nefrología Pediátrica, Hospital Universitario de Badajoz, Badajoz, Spain. ${ }^{15}$ ServicioNefrología Infantil, Hospital Infantil Gregorio Marañón, Madrid, Spain. ${ }^{16}$ Unidad de Nefrología Pediátrica, Hospital Virgen de La Salud, Toledo, Spain. ${ }^{17}$ Servicio Nefrología infantile, Hospital Universitario Infantil La Paz, Madrid, Spain. ${ }^{18}$ Servicio Nefrología, Hospital Severo Ochoa, Leganés, Spain. ${ }^{19}$ Servicio Pediatría, Hospital Vega Baja, Orihuela, Spain.

Published online: 01 April 2021

\section{Reference \\ 1. Rodríguez-Rubio, et al. Phenotypic characterization of X-linked hypophosphatemia in pediatric Spanish population. Orphanet J Rare Dis. 2021;16:104. https://doi.org/10.1186/s13023-021-01729-0.}

\section{Publisher's Note}

Springer Nature remains neutral with regard to jurisdictional claims in published maps and institutional affiliations.

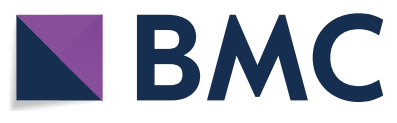

(c) The Author(s) 2021. This article is licensed under a Creative Commons Attribution 4.0 International License, which permits use, sharing, adaptation, distribution and reproduction in any medium or format, as long as you give appropriate credit to the original author(s) and the source, provide a link to the Creative Commons licence, and indicate if changes were made. The images or other third party material in this article are included in the article's Creative Commons licence, unless indicated otherwise in a credit line to the material. If material is not included in the article's Creative Commons licence and your intended use is not permitted by statutory regulation or exceeds the permitted use, you will need to obtain permission directly from the copyright holder. To view a copy of this licence, visit http://creativecommons.org/licenses/by/4.0/. The Creative Commons Public Domain Dedication waiver (http://creativecommons.org/publicdomain/zero/1.0/) applies to the data made available in this article, unless otherwise stated in a credit line to the data. 